\title{
FORMAÇÃO ESTÉTICA DE EDUCADORES: DIÁLOGOS ENTRE OS FAZERES DA ARTE E DA EDUCAÇÃO PARA A INFÂNCIA
}

THE AESTHETIC EDUCATION OF TEACHERS: DIALOGUES BETWEEN ART AND EDUCATION FOR CHILDREN

\author{
Simone Cristiane Silveira Cintra \\ Doutora em Educação pela UNICAMP. \\ Eliane Dias Santana Debus \\ Doutora em Letras pela PUC/RS. Docente do Programa de Pós-Graduação em Educação da UFSC. \\ Programa de Pós-Graduação em Educação \\ Universidade Federal de Santa de Catarina (UFSC) \\ Florianópolis - SC - Brasil \\ Endereços: \\ Rua Lauro Linhares, 897, Ap 304-D \\ Trindade - Florianópolis - SC \\ CEP: 88036001 \\ Rua Ilha Sul, 62 \\ Campeche - Florianópolis - SC \\ CEP: 88065-290 \\ E-mails: \\ simonescintra@gmail.com \\ elianedebus@hotmail.com
}

RESUMO

Neste artigo apresentamos e trazemos à discussão aspectos de uma ação formativa desenvolvida com o Grupo de Estudos do Programa de Educação Tutorial do Curso de Pedagogia da UFSC (GEPET). Esta ação integra uma pesquisa de pós-doutorado, por meio da qual temos investigado e refletido sobre a formação artístico-cultural do educador da infância. Nossa reflexão se dá a partir de atividades corporais; lúdicas; teatrais; de fruição e criação artística, vivenciadas pelas estudantes junto à narrativa Plic, Plic: um barulho da chuva, de Liliana I acocca e está fundamentada por estudos sobre linguagem teatral; literatura para a infância e interfaces entre a arte e a formação de educadores. Como resultados desse processo investigativo, procuramos indicar e discutir as implicações que o brincar e o encenar - junto a narrativas literárias produzidas para a infância - podem trazer ao processo de formação de educadores da infância, em especial, às formas como esses podem vir a desenvolver sua dimensão estética em diálogo com seus modos de compreender, construir e vivenciar práticas educativas com as crianças.

PALAVRAS-CHAVE: Formação Estética de Educadores. Literatura para a infância. Teatro. 
process is part of a post-doctoral study that investigated and reflected on the artistic-cultural development of children's educators. Our reflection is grounded in corporeal, ludic, theatrical, fruition, and artistic creation activities undertaken by students from the narrative Plic, Plic: um barulho da Chuva, by Liliana Lacocca, which is based on studies of theatrical language, children's literature, and interphases between art and teacher education. As the results of this investigative process, we attempt to point out and discuss implications that playing and staging - children's literary narratives as a case in point - can bring about in the process of teacher education for children, particularly regarding the way in which educators develop their aesthetic dimension, in a dialogue with their means of understanding, constructing, and experiencing educational practices in the context of children's education.

KEY-WORDS: Aesthetic Development of Teachers. Children's Literature. Theater.

INTRODUÇÃO

"Por meio dos sentidos suspeitamos o mundo", escreveu Bartolomeu Campos de Queiroz (2009) no início de Os cinco sentidos, oferecendo-nos, dentre tantas, mais uma bela imagem poética. Suspeitar o mundo; aceitá-lo em sua condição polissêmica, mutável e inapreensível em seu todo nos parece vital àqueles que educam, em especial, àqueles que produzem e vivenciam processos educativos junto às crianças no âmbito da educação formal.

Sem desconsiderar as mudanças paradigmáticas que vimos presenciando no campo educacional, tanto em nível teórico, como prático, a existência de instituições de educação básica em nosso país, ainda, alicerçadas por ideias e ações notoriamente pragmáticas e instituidoras de um modo de pensar único e absoluto, é um fato a ser debatido e questionado. Como aponta Zanella (2006, p. 146),

As instituições de escolarização formal [...], historicamente têm servido à limitação de olhares, à restrição do que é múltiplo, à negação do que é plural, ao controle do que poderia ali ter expressão. Seus espaços, a estética das paredes, luzes e cores, os movimentos permitidos e proibidos, os rituais que pouco se renovam, as (poucas) falas consentidas, os saberes que podem ali transitar e os que são desautorizados, os corpos acolhidos e os condenados à reprovação, o que se fala e o que se silencia, vários são os aspectos que constituem as (im)possibilidades (in) sensíveis de alunos(as), professores(as) e todas as pessoas que (re)produzem cotidianamente as escolas e aí se (re)produzem.

As condições elencadas pela autora não se restringem às escolas, podendo ser também identificadas em instituições de educação infantil. Exemplo disso pode ser evidenciado em atividades, ainda presentes, como desenhar, pintar, modelar a partir de modelos apresentados pelo educador.

Pretendemos, com este texto, abordar e discutir o que a nós se apresenta como uma das formas possíveis e profícuas para pensarmos e construirmos uma educação formal que, entre outros aspectos, considere e incorpore a divergência, a polissemia, a suspeita do mundo. Referimo-nos ao reconhecimento e à criação de condições para o desenvolvimento da dimensão estética de todos aqueles que constituem os espaços educativos e por eles são constituídos.

As reflexões aqui pretendidas enfocam o desenvolvimento da dimensão estética de educadores em formação inicial, assim como às possíveis implicações deste desenvolvimento ao incessante processo de tornar-se educador. Nosso trabalho reporta-se, de modo especial, ao educador da infância ${ }^{1}$, entretanto muitos aspectos abordados neste texto podem, ao nosso modo de compreendêlos, vir a dialogar com a formação estética de outros educadores, de crianças e adolescentes.

Tomamos, como ponto de partida, atividades vivenciadas por estudantes do curso de Pedagogia da Universidade Federal de Santa Catarina (UFSC), por meio de uma ação formativa da pesquisa de pós-doutorado Teatro, Literatura para a Infância e Prática Educativa: diálogo entre fazeres². Essa ação teve por objetivo ampliar as oportunidades e as possibilidades de experiências estéticas na formação de educadores a partir de vivências de fruição e criação artística, com ênfase na literatura produzida para a infância e no fazer teatral. 


\section{EXPERIÊNCIAS DE FRUIÇÃO E CRIAÇÃO ARTÍSTICA NA FORMAÇÃO INICIAL DE EDUCADORES}

Durante o segundo semestre letivo de 2011 realizamos - junto ao Grupo de Estudos do Programa de Educação Tutorial (GEPET) e com a participação de 28 estudantes pertencentes a todas as fases de graduação em Pedagogia - o curso "Estudos e Práticas Teatrais e Literárias", compreendendo sete encontros dedicados, principalmente, à fruição de obras literárias produzidas para a infância e a experimentação de elementos da linguagem teatral.

Em nosso terceiro encontro foram desenvolvidas atividades corporais, lúdicas, teatrais, de fruição e criação artística, vivenciadas pelas estudantes junto à narrativa Plic, Plic: um barulho da chuva, de Liliana Iacocca (1995). Iniciamos o dia com uma série de atividades baseadas em movimentos de alongamento e aquecimento corporal, àquela altura já conhecidos e incorporados pelas estudantes como imprescindível ao processo de aproximação e experimentação dos elementos da linguagem teatral ao qual nos dedicávamos junto às experiências de fruição literária e criação de cenas teatrais deflagradas pelas obras fruídas.

Terminadas essas atividades, brincamos de roda junto à cantiga:

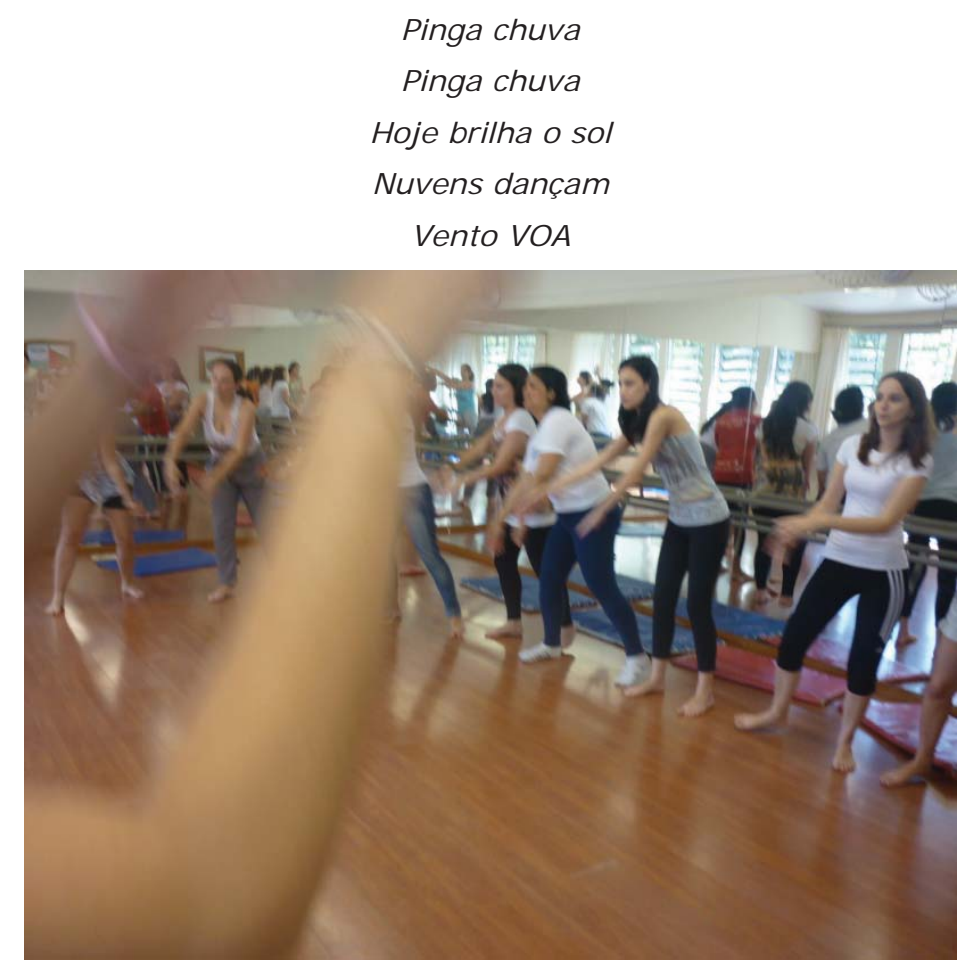

Cantando e Dançando em Roda

Fonte: Arquivo da pesquisa.

A cantiga de roda foi apresentada às estudantes na intenção de introduzir, de forma corporal e lúdica, alguns dos elementos da natureza também poetizados pela narrativa Plic, Plic: um barulho da chuva, lida logo após a brincadeira. 


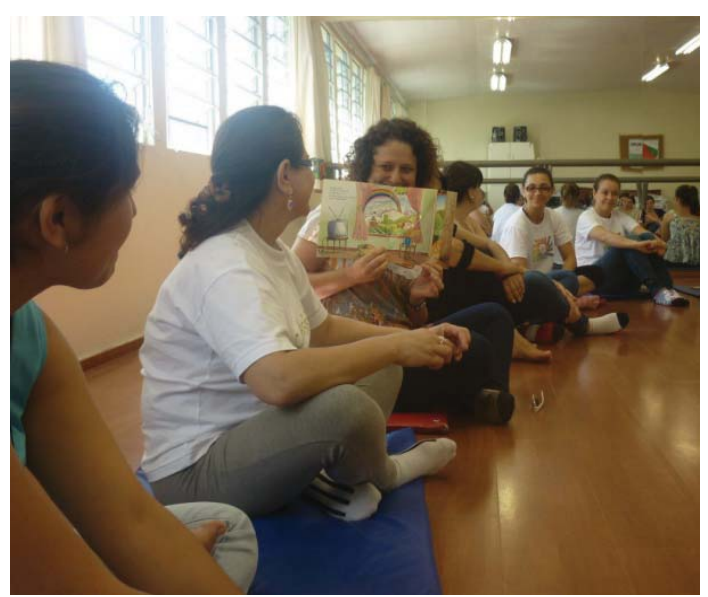

Ouvir, Ver, Fruir

Fonte: Arquivo da pesquisa.

Tanto a cantiga como a narrativa dizem sobre a chuva, o sol, as nuvens e os seus barulhos e movimentos. Todos esses dizeres foram, então, transformados em motivação, inspiração ou mote para as brincadeiras e as cenas teatrais que as sucederam.

Nas duas primeiras brincadeiras as estudantes criaram sons vocais e movimentos corporais inspirados pela cantiga e/ou pela narrativa. Na primeira, dividiram-se em dois grupos, sendo que cada um se mantinha posicionado em duas fileiras, uma de frente para a outra. Sem qualquer combinação prévia, uma estudante de cada grupo criava um som vocal e um movimento corporal que deveria ser reproduzido, a princípio, somente pelo seu grupo. Assim que ambos os grupos iniciavam seus sons e seus movimentos, caminhavam ao encontro um do outro e este encontro produzia a mudança: os grupos abandonavam sua criação original e passavam a reproduzir os sons e os movimentos do outro grupo. Na segunda, a movimentação ocorreu por toda a sala e, como na brincadeira tradicional de "siga o mestre", cada uma das estudantes teve o seu momento de ser o mestre e ver sua criação sonora e corporal ser seguida por todo o grupo. Colocamos, abaixo, o registro fotográfico da segunda brincadeira:

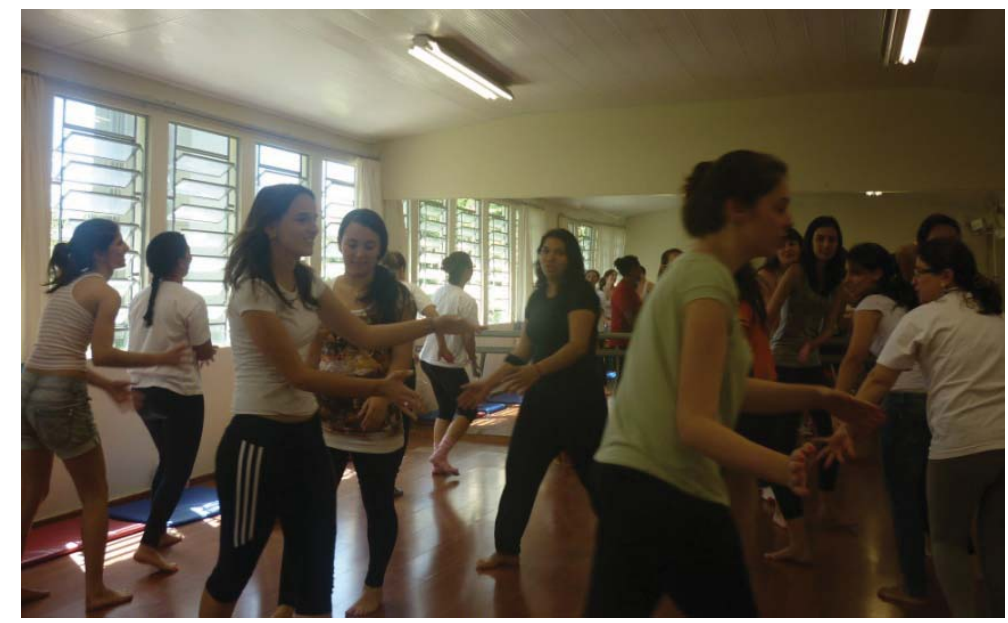

Brincando com Sons e Movimentos da Natureza Fonte: Arquivo da pesquisa.

Depois das brincadeiras, as estudantes criaram frases também inspiradas na narrativa e/ou na cantiga e que diziam sobre a chuva, o vento, o sol... suas cores, cheiros, sensações. Essas frases transformaram-se em material de criação para as duas próximas atividades. Primeiro, uma dinâmica na qual diferentes formas de dizer uma frase puderam ser experienciadas e, depois, a elaboração e a apresentação de cenas teatrais. Durante a primeira atividade, duas estudantes corriam, em 
sentido contrário, em volta de uma roda formada pelas demais participantes e, ao ouvirem palmas, entravam na roda e diziam suas frases, procurando variar os ritmos da fala e a entonação da voz. Para a criação das cenas teatrais, as estudantes subdividiram-se em quatro grupos e utilizaram-se das frases criadas pelas participantes do seu grupo, ficando livres para escolherem uma ou mais frases, partes de várias ou até criarem outros sons, frases melódicas, onomatopeias, etc., para compor as cenas, apresentadas ao final da aula. As imagens abaixo mostram momentos de três diferentes cenas criadas pelas estudantes.
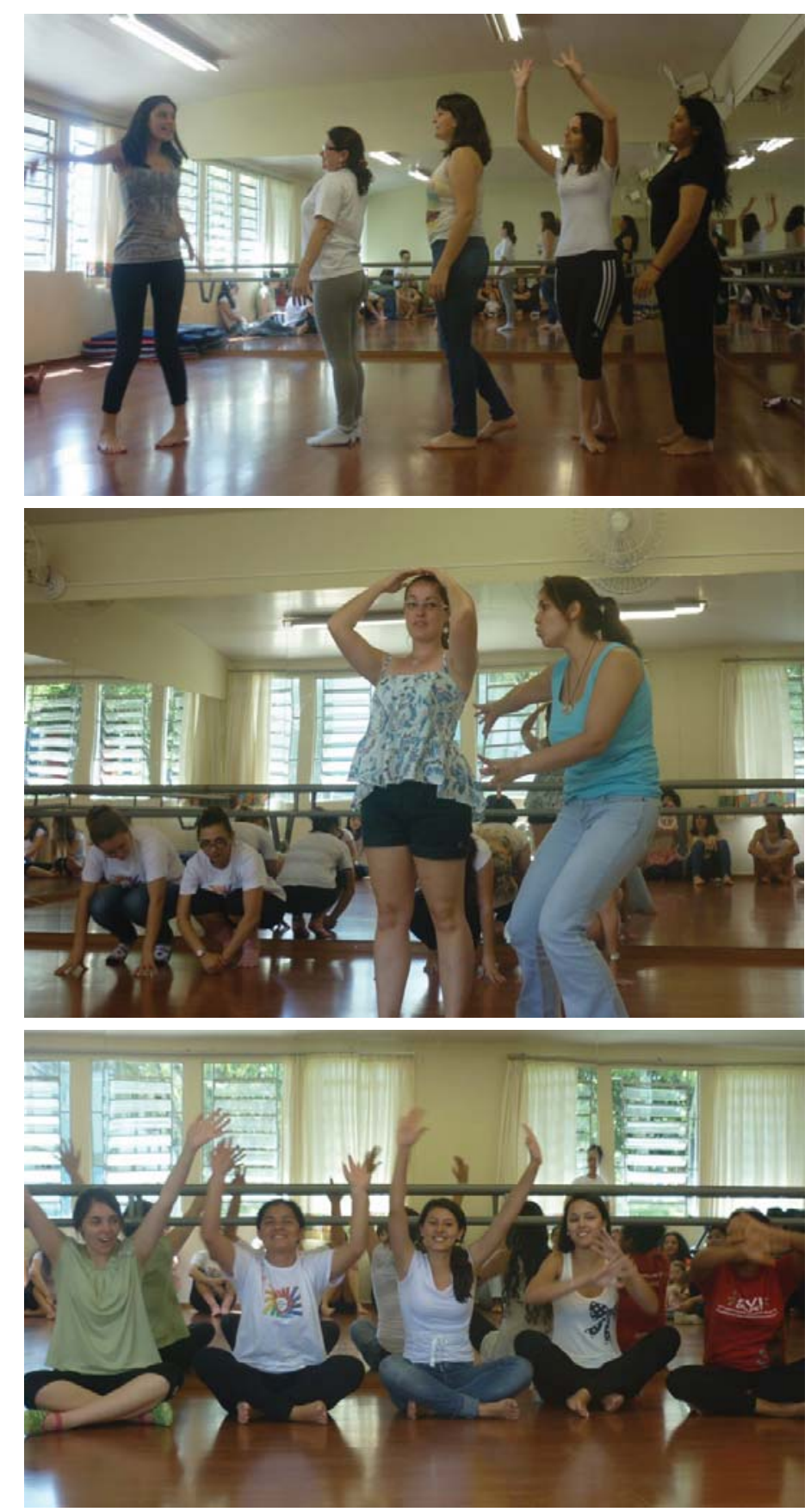

Cenas Teatrais

Fonte: Arquivo da pesquisa.

No final de cada encontro, as estudantes realizaram um registro reflexivo sobre as atividades do dia, sem um roteiro prévio ou perguntas. Puderam, também, refletir sobre o curso como um todo, elaborando um diário entregue em nossa última aula. Para a criação deste diário, sugerimos 
que, além de palavras, as estudantes pudessem utilizar imagens, desenhos, poesias e, desta forma, registrar e refletir sobre as experiências vividas de diferentes maneiras, atendo-se aos fatos e às sensações, aos sentimentos, às escolhas e aos anseios.

Encontramos nos registros produzidos em aula uma presença acentuada de termos e situações como: criatividade, interação em grupo, corpos mais soltos e livres ou com necessidade de estarem mais soltos e mais livres para a criação. Colocamos, abaixo, trechos de diferentes reflexões nos quais essa presença pode ser observada.

Estudante 1: Gosto das atividades de criação em grupo. É um tempo para interagirmos e utilizarmos nossa criatividade.

Estudante 2: Essas três atividades trabalharam com a criatividade, com movimentos do corpo, por isso que eu gostei.

Estudante 3: Hoje essa aula foi muito divertida, mexeu com nossa criatividade para movimentos combinados com sons.

Estudante 4: Foi um encontro divertido, a interação do grupo foi maior e o uso da criatividade nas atividades também foi bem legal.

Estudante 5: Tenho dificuldade para me expressar (na última dinâmica), gostaria de utilizar o corpo, mas tenho dificuldade.

A presença desses termos e situações traz indícios que nos permitiram refletir sobre as atividades aqui descritas e, também, sobre o curso como um todo. Todos os encontros foram organizados de modo a potencializar o (re)encontro das estudantes com a fruição e a criação artística por meio das linguagens da arte, principalmente, a literária e a teatral. Nesta aula, em especial, as atividades foram bastante corporais e buscaram explorar a questão da sonoridade, abordada na narrativa literária, utilizando somente o corpo. Essa exploração foi percebida e valorada pelas estudantes, assim como a dificuldade por ela deflagrada. Uma dificuldade estreitamente relacionada ao predomínio de situações, incluindo as vividas no âmbito da formação escolar e acadêmica, excessivamente centradas em relações práticas-utilitárias (ZANELLA, 2006). Grande parte dos futuros educadores carrega em seus corpos e atitudes vivências escolares "centradas na razão e pouco afeitas a experiências com o corpo, com os sentidos e a criação" (CI NTRA; ALBANO, 2010). Essa é uma questão que tem sido abordada por diferentes autores (ALBANO, 2012; CINTRA; ALBANO, 2010; DEBUS, 2006; LEITE; OSTETTO, 2004; OSTETTO, 2006 e 2010; ZANELLA et al., 2006, entre outros) e nos leva a pensar a indissociável relação entre a formação estética do educador da infância e a construção de práticas educativas com crianças. Como aponta Ostetto (2010):

O professor precisa estar alimentado e conectado com a sua expressão, precisa reconquistar o seu poder imaginativo, se pretende e deseja garantir a expressão e a criação das crianças. A educação do educador é essencial e, no que diz respeito à arte, passa necessariamente pelo reencontro do espaço lúdico dentro de si, pela redescoberta das suas linguagens, do seu modo de dizer e expressar o mundo (p.72-73).

A palavra "criatividade" aparece em quatro dos cinco trechos transcritos acima, fato que nos pareceu significativo, podendo indicar que as atividades vivenciadas trouxeram a possibilidade do exercício criativo. Entendemos, e aqui utilizamos, a palavra criatividade na sua acepção de capacidade criadora, o conceito de criatividade como "um potencial inerente ao homem, e a realização desse potencial [como] uma de suas necessidades" (OSTROWER, 2003, p. 5). Sem, contudo, desconsiderar que

(...) a possibilidade de criar resulta de um aprendizado que pode ocorrer ao longo da história de cada pessoa. Esta, por sua vez, está irremediavelmente ligada ao contexto histórico e, portanto, às condições concretas de que dispõe o sujeito para atuar e conhecer, já que a atividade caracteristicamente humana é semioticamente mediada, enfim, cultural. (ZANELLA et al., 2003, p. 144).

Embora nossa ação educativa, junto às futuras educadoras, tenha ocorrido no âmbito das linguagens artísticas, buscamos refletir sobre a capacidade criadora humana de uma forma ampla, uma vez que entendemos que a fruição e a criação artística podem vir a ampliar a nossa criatividade, tanto no fazer artístico, como em outros fazeres de nossas vidas. Uma criatividade que, no caso do educador, pode, ainda, ajudá-lo a acolher e a criar condições para a total expansão das potencialidades criativas das crianças com as quais convive. 
Como pudemos observar e refletir junto à experiência vivida por nossas alunas, o brincar e o encenar junto a narrativas literárias potencializam a experiência do criar, do "dar forma a algo novo", tratando-se esse novo "de novas coerências que se estabelecem para a mente humana, fenômenos relacionados de modo novo e compreendidos em termos novos" (OSTROWER, 2003, p. 9). Uma potência, nem sempre encontrada em atividades que constituem a vida e a formação dos educadores, uma vez que estas se destinam, na maioria das vezes, às repostas e às atitudes conhecidas; usuais, nas quais o novo não encontra espaço. As práticas educativas com crianças, por sua vez, não podem ser desprovidas do novo, de ideias e ações novas, inusitadas ou nunca antes exploradas. Ações repetitivas, sem a força da novidade, não condizem com o modo de ser da infância, pois, como sintetiza Sonia Kramer (2007),

\section{(...) as crianças viram as coisas pelo avesso e, assim, revelam a possibilidade de criar. Uma cadeira de cabeça para baixo se torna barco, foguete, navio, trem, caminhão. Aprendemos, assim, com as crianças, que é possível mudar o rumo estabelecido das coisas (p.15).}

A criança, como coloca Glória Kirinus (2011), é um “Ser em estado de poesia" (p. 32), nesse sentido, (re)encontrar-se e exercitar a criação artística podem aproximar o adulto-educador do modo de ser e aprender da criança. Para tanto, faz-se necessário que a poesia volte a fazer parte da sua vida, que a criação embrenhe-se por suas atividades cotidianas, acompanhando-o e (re) direcionando-o à sua própria dimensão estética. Pudemos observar, junto aos diários reflexivos de duas de nossas alunas, a ação da criação para além do momento de aula. No primeiro caso, a estudante diz da permanência da vivência estética por todo o seu dia, indicando a amplitude da arte e sua capacidade de nos tocar de forma sensível e profunda.

Diário 1: trecho do registro do dia 26/10/2011

A aula trouxe: Sol! Chuva! Vento! Fiuuuuu... Calor! Beleza! Cor! Brisa Suave e Agitada! Frio!

O Plic, Plic tomou forma durante todo o dia, parecia que eu continuava a vivenciar as palavras da história, as frases ditas por cada pessoa e, também, o meu sentimento trazido pela história.

E, no segundo, vemos a fruição literária; a cantiga de roda; as brincadeiras e a criação teatral inspirando, subsidiando, provocando a criação de um poema:

Diário 2: transcrição integral do registro do dia 26/10/2011

Movimentar o corpo

Pinga chuva, chuva pinga mexe o corpo e respinga

No sol ou na sombra e na restinga

Dia de sol, dia de chuva

usar guarda-chuva banhar na chuva usar guarda-sol e não luva

Mexe o corpo, mexe a cabeça fazendo malabares assim que começa

Som fraco som forte chove no norte chove sem parar

De dia, de noite tudo ou nada sonhando acordada com a chuva molhada 
O vivenciar o poema pode levar à escrita do poema, como se observa no exemplo acima; desse modo estão imbricados aspectos relativos ao corpo (gesto, movimento), bem como aqueles ligados à escrita: o ser poético que habita em cada um de nós.

\section{CONSIDERAÇÕES FINAIS}

Nossas ações educativas objetivaram promover o encontro das futuras educadoras com a literatura produzida para a infância mediado pela cantiga de roda, pela brincadeira e pela criação teatral. Mas, também, o encontro com a cantiga de roda, com a brincadeira e a criação teatral mediado pela literatura produzida para a infância. Buscamos possibilitar a experiência da fruição literária junto ao brincar, à criação artística e à experiência do brincar e da criação artística junto à fruição literária. Experiências nas e pelas quais elementos de linguagens artísticas foram colocados em diálogo, na intenção de potencializar a experimentação e a compreensão da "arte como linguagem, como uma forma de representação e expressão, que opera por meio de cores, formas, linhas e volumes, gestos e sons para criar imagens" (ALBANO, 2004, p.46).

Experimentar e compreender a arte como linguagem, como fala poética - não restrita à informação e/ ou à transmissão de conhecimentos ou condutas; que produz imagens, desloca sentidos, (re) inventa situações e que, assim como os conhecimentos, as informações e as condutas, media nossa relação com o mundo e com nós mesmos - pode vir a aproximar o adulto da criança, que vive em estado de poesia e, também, ajudá- lo a redescobrir a sua própria fala poética. Entretanto essa experimentação e compreensão necessitam ser instigadas, provocadas, amplamente oferecidas, passando a compor a vida dos (futuros) educadores e a desenvolver sua dimensão estética de forma contínua, valorizada, incorporada aos seus processos de formação, dentro e fora das instituições educativas.

REFERÊNCIAS

ALBANO, Ana Angélica. A arte como base epistemológica para uma pedagogia da infância. In: Caderno Temático de formação II: Educação Infantil construindo a Pedagogia da Infância no município de São Paulo. Prefeitura Municipal de São Paulo. Secretaria Municipal de Educação. Janeiro de 2004. Disponível em: < http://portalsme. prefeitura.sp.gov.br/Documentos/BibliPed/Publicacoes2001_2007/CadernoTematico_2. pdf>. Acesso em: 03/09/2012.

Ana Angélica. O espaço do desenho a educação do educador. 15. ed. São Paulo: Loyola, 2012.

CINTRA, Simone C. S. e ALBANO, Ana Angélica. Docência e Criação: diálogos entre fazeres. In: GONÇALVES, Tatiana Fecchio; DIAS, Adriana Rodrigues (Org). Entre linhas, formas e cores: arte na escola, Campinas, SP: Papirus, 2010, p.19-33.

DEBUS, Eliane. Festaria de brincança: a leitura literária na educação infantil. São Paulo: Paulus, 2006.

IACOCCA, Liliana. Plic Plic: um barulho da chuva. II: Michele. 5a ed. São Paulo: Ática, 1995.

KIRINUS, Glória. Synthomas de poesia na infância. São Paulo: Paulinas, 2011.

KRAMER, Sonia. A infância e sua singularidade. In: MEC. Ensino Fundamental de Nove Anos: orientações para a inclusão da criança de seis anos de idade. 2007. Disponível em: < http://portal.mec.gov.br/seb/ arquivos/pdf/Ensfund/ensifund9anobase final. pdf>. Acesso em: 03/09/2012.

LEITE, Maria Isabel; OSTETTO, Luciana E. Formação de Professores: o convite da arte. In: OSTETTO, Luciana E.; LEITE, Maria Isabel (Org). Arte, Infância e formação de professores: autoria e transgressão. Campinas, SP: Papirus, 2004, p.11-24. 
OSTETTO, Luciana E. Educação infantil, arte e criação: ensaios para transver o mundo. In: Diretrizes educacionais pedagógicas para educação infantil. Prefeitura Municipal de Florianópolis. Secretaria Municipal de Educação. Florianópolis: Prelo Gráfica \& Editora Ltda., 2010.

A arte no itinerário da formação de professores: acender coisas por dentro. Reflexão e Ação, Santa Cruz do Sul, SC, vol.14, n.1, p.29-43, jan./jun. 2006.

OSTROWER, Fayga. Criatividade e Processos de Criação. 17. ed. Petrópolis, RJ: Vozes, 2003.

QUEI ROZ, Bartolomeu Campos de. Os cinco sentidos. São Paulo: editora Global. 2009.

ROCHA, Eloísa Candal. Educação e Infância: trajetórias de pesquisa e implicações pedagógicas. In: ROCHA, Eloísa Candal; KRAMER, Sonia (Org.). Educação Infantil: enfoques em diálogo. Campinas, SP: Papirus. 2011, p.367-384.

ZANELLA, Andréa V. Sobre olhos, olhares e seu processo de (re)produção. In: LENZI, Lúcia Helena C. et al. Imagem: intervenção e pesquisa. Florianópolis: Editora da UFSC: NUP/CED/UFSC, 2006, p.139-150.

ZANELLA, Andréa Vieira et al. Concepções de criatividade: Movimentos em um contexto de escolarização formal. Psicologia em Estudo, Maringá, v. 8, n. 1, p. 143-150, jan./jun. 2003. Disponível em: <http:// www.scielo.br/pdf/pe/v8n1/v8n1a17. pdf>. Acesso em: 03/09/2012.

Relações estéticas, atividade criadora e constituição do sujeito: algumas reflexões sobre a formação de professores(as). Cadernos de Psicopedagogia, São Paulo, v.6, n.10, p. 01-17, 2006. Disponível em: <http://pepsic.bvsalud.org/scielo.php?script=sci_arttext\&pid=S1676-10492006000100002.>. Acesso em: 03/09/ 2012.

NOTAS

1 Usamos o termo educador da infância para referirmo-nos aos professores da Educação Infantil e dos anos iniciais do Ensino Fundamental. A opção por essa nomenclatura fundamenta-se em estudos e pesquisas, realizados no âmbito da Pedagogia da Infância, dedicados à educação das crianças nas creches, pré-escolas e nos cinco primeiros anos do ensino fundamental. Esta Pedagogia, compreendida como campo específico na área da Educação, busca pela "articulação de campos teóricos que permitam captar o conjunto de aspectos envolvidos no processo educativo (social, familiar, cultural, psicológico, biológico etc.), no sentido de compreender as crianças e sua infância (ROCHA, 2011, p.374)".

2 Desenvolvida junto ao Programa de Pós-graduação em Educação da UFSC (PPGE), com apoio do Programa de Reestruturação e Expansão das Universidades Federais (REUNI).

Artigo recebido em $01 / 08 / 2012$

Aprovado em 10/09/2012 